\title{
Effect of recombinant human GH on circulating granulocyte colony-stimulating factor and neutrophils in patients with adult GH deficiency
}

\author{
Motoi Sohmiya, Ippei Kanazawa and Yuzuru Kato \\ Department of Endocrinology, Metabolism and Hematological Oncology, Shimane University School of Medicine, Izumo 693-8501, Japan \\ (Correspondence should be addressed to M Sohmiya; Email: motoi@med.shimane-u.ac.jp)
}

\begin{abstract}
Background: We previously reported that short-term continuous subcutaneous infusion (CSI) of recombinant human growth hormone (rhGH) increased plasma erythropoietin levels and hemoglobin concentrations in patients with adult GH deficiency. In the present study, we investigated the effect of rhGH on plasma granulocyte colony-stimulating factor (G-CSF) levels and neutrophil counts in patients with adult GH deficiency.

Methods: rhGH was administrated for 1 year in six patients with adult GH deficiency (age range, 24-69 years; mean \pm S.E.M., $51.7 \pm 5.8$ years; two males and four females) by means of CSI at a rate of $0.25 \mathrm{U} / \mathrm{kg}$ per week. Blood samples were obtained in the morning after overnight fasting every month before and after the start of rhGH administration. Plasma GH, insulin-like growth factor I (IGF-I) and G-CSF levels, and neutrophil counts, were measured.

Results: Mean ( \pm S.E.M.) plasma GH levels increased from $0.26 \pm 0.14$ to $2.28 \pm 0.20 \mu \mathrm{g} / \mathrm{l} 1 \mathrm{month}$ after the start of rhGH administration. An increase of the plasma GH levels was accompanied by an increase in the plasma IGF-I levels from $64.7 \pm 8.5$ to $293.3 \pm 80.6 \mu \mathrm{g} / \mathrm{l}$. Plasma G-CSF levels increased at 2, 3, 8, 9 and 10 months after the start of rhGH administration compared with $28.6 \pm 11.0 \mathrm{ng} / \mathrm{l}$ at time 0 . The neutrophil counts increased at 2, 3, 7, 8, 9, 11 and 12 months after the start of rhGH administration compared with $2822 \pm 377$ neutrophils/ $\mu \mathrm{l}$ at time 0 .

Conclusion: rhGH administration increased plasma G-CSF levels and neutrophil counts. GH and/or IGF-I might stimulate neutrophil production and/or release via G-CSF.
\end{abstract}

European Journal of Endocrinology 152 211-215

\section{Introduction}

Growth hormone (GH) exerts an influence on the hematopoietic system as regards the normal differentiation and function of erythroid, myeloid and lymphoid cells $(1-4)$. GH deficiency is often associated with anemia, leukopenia and thrombocytopenia (2-4). Furthermore, GH administration increased hemoglobin concentration in patients with adult GH deficiency (5, 6 ), and enhanced the function of myeloid cells and neutrophils $(3,4)$. We previously reported that continuous subcutaneous infusion of recombinant human GH (rhGH) increased plasma erythropoietin levels and hemoglobin concentrations in patients with adult $\mathrm{GH}$ deficiency (6). However, the effect of GH on neutrophil production in vivo in patients with adult $\mathrm{GH}$ deficiency is not yet fully understood.

Granulocyte colony-stimulating factor (G-CSF) is a hematopoietic growth factor, a glycoprotein with a molecular mass of about $20000 \mathrm{Da}$ that stimulates the production and functional activation of neutrophils (7-9). Recent studies have demonstrated that recombinant G-CSF is effective in the treatment of patients with neutropenia. G-CSF is known to be produced by monocytes (10), endothelial cells (11), fibroblasts (12) and bone marrow stromal cells (13). However, the main source of circulating G-CSF remains to be elucidated. G-CSF secretion is stimulated by interleukin-1 (IL-1) (11-13), tumor necrosis factor $\alpha$, bacterial endotoxin (14) and prednisolone (15), and inhibited by IL-4, IL10 and IL-13 (16). However, there are no reports on the relationship between $\mathrm{GH}$ and G-CSF.

GH stimulates the development and function of granulocytes (17). The GH receptor is also present on monocytes, fibroblasts, neutrophils and lymphocytes (18). Therefore, GH administration might exert an influence on both G-CSF secretion and the neutrophil count. However, the relationship between neutrophil production and plasma G-CSF levels during rhGH administration has not been reported. 
In the present study, we investigated the effect of rhGH on plasma G-CSF levels and the neutrophil count in patients with adult GH deficiency. This first report is a pilot study on the relationship between plasma G-CSF levels and rhGH treatment in patients with adult GH deficiency.

\section{Materials and methods}

\section{Subjects}

Six patients with adult GH deficiency (age range, 24-69 years; mean \pm s.e., $51.7 \pm 5.8$ years; two males and four females) were studied. The subjects consisted of five patients with pan-hypopituitarism after pituitary tumor resection, and one additional patient with Sheehan's syndrome. The tumors were completely resected when they were evaluated histologically and by magnetic resonance imaging (MRI) after the surgery.

After insulin-induced hypoglycemia and arginine loading, peak GH levels were less than $3 \mu \mathrm{g} / \mathrm{l}$ in all of the subjects. In addition, all subjects had been diagnosed with a GH deficiency more than 18 months before the study began. Hormones other than $\mathrm{GH}$ were maintained within the normal range. Thyroid hormone levels and adrenocortical hormone levels were maintained within the normal range by appropriate replacement with L-thyroxine and hydrocortisone, respectively, for more than 1 year in all of the patients. The dosage of these drugs was not altered during the experimental period. None of the patients were given any ferric medicine during the experimental period. Bone marrow examination revealed normal myelograms in all of the subjects. The present study was in accordance with the Helsinki Declaration of 1975. Written informed consent was obtained from all of the subjects prior to participation in the study.

\section{Study protocol}

22 kDa rhGH (Norditropin; Novo Nordisk Co., Bagsværd, Denmark) was dissolved in $0.9 \%$ saline and administrated to the subjects by means of continuous subcutaneous infusion (CSI) at a flow rate of $0.25 \mathrm{U} / \mathrm{kg}$ per week $(1.79 \mathrm{U} /$ day per $50 \mathrm{~kg}$ body weight) for 12 months using a portable syringe pump (SP-3HQ; Nipro Co., Osaka, Japan) that had been inserted into the abdominal wall.

Blood samples were obtained in the early morning after an overnight period of fasting. These samples were obtained both before and every week after the start of rhGH administration for 1 month, and then the same protocol was followed for each of the next 11 months. Plasma GH, insulin-like growth factor I (IGF-I) and G-CSF levels, and neutrophil counts were monitored once a month. Lymphocyte, monocyte and eosinophil counts were also measured. Complete blood count ( $\mathrm{CBC}$ ), C-reactive protein, erythrocyte sedimentation rate and other blood-chemistry analyses were carried out on a monthly basis. Body weight, blood pressure, and subjective and objective symptoms were also evaluated every month.

\section{Assays}

Plasma GH levels were measured by enzyme immunoassay as described previously (19). The minimum detectable quantity was $0.01 \mu \mathrm{g} / \mathrm{l}$ using a $20 \mu \mathrm{l}$ plasma sample. Intra- and inter-assay coefficients of variation were 4.3 and $5.2 \%$, respectively.

Plasma IGF-I levels were measured by specific RIA after acid-ethanol extraction, as described previously (20). The minimal detectable quantity was $30 \mu \mathrm{g} / \mathrm{l}$ using a $50 \mu \mathrm{l}$ plasma sample. Intra- and inter-assay coefficients of variation were 6.3 and $7.2 \%$, respectively. Normal ranges of plasma IGF-I levels in our laboratory were $202.8 \pm 70.6$ and $198.6 \pm 91.8 \mu \mathrm{g} / \mathrm{l}$ in males and females, respectively.

Plasma G-CSF levels were measured by sensitive enzyme immunoassay as described previously (15). The minimum detectable concentration was $1 \mathrm{ng} / \mathrm{l}$ using a $20 \mu \mathrm{l}$ plasma sample. Intra- and inter-assay coefficients of variation were 2.7 and $5.6 \%$, respectively. The mean recovery was $96.8 \%$. There was no crossreactivity with macrophage colony-stimulating factor, granulocyte-macrophage colony-stimulating factor, interleukin- $1 \partial$ or erythropoietin at a concentration of $1 \mu \mathrm{g} / \mathrm{ml}$.

Neutrophil counts as well as CBC, C-reactive protein, erythrocyte sedimentation rate and other blood-chemistry analyses were measured by conventional methods in our hospital laboratory.

\section{Statistical analysis}

All values are means \pm S.E.M. The data were analysed with a Dunnett post-hoc test in combination with ANOVA. $P<0.05$ was considered significant.

\section{Results}

As shown in Fig. 1, plasma GH and IGF-I levels were increased significantly $(P<0.0001)$. Plasma GH levels (mean \pm S.E.M.) increased from $0.26 \pm 0.14$ to $2.28 \pm 0.20 \mu \mathrm{g} / \mathrm{l}$ at 1 month after the start of rhGH administration, which was accompanied by an increase in plasma IGF-I levels from $64.7 \pm 8.5$ to $293.3 \pm 80.6 \mu \mathrm{g} / \mathrm{l}$. Steady-state plasma GH and IGF-I levels were obtained during the next 11 months. As shown in Fig. 2, plasma G-CSF levels were increased significantly $(P=0.030)$. Plasma G-CSF levels increased at 2, 3, 8, 9 and 10 months after the start of rhGH administration compared with $28.6 \pm 11.0 \mathrm{ng} / \mathrm{l}$ at time 0 . As shown in Fig. 3, the neutrophil counts were increased 


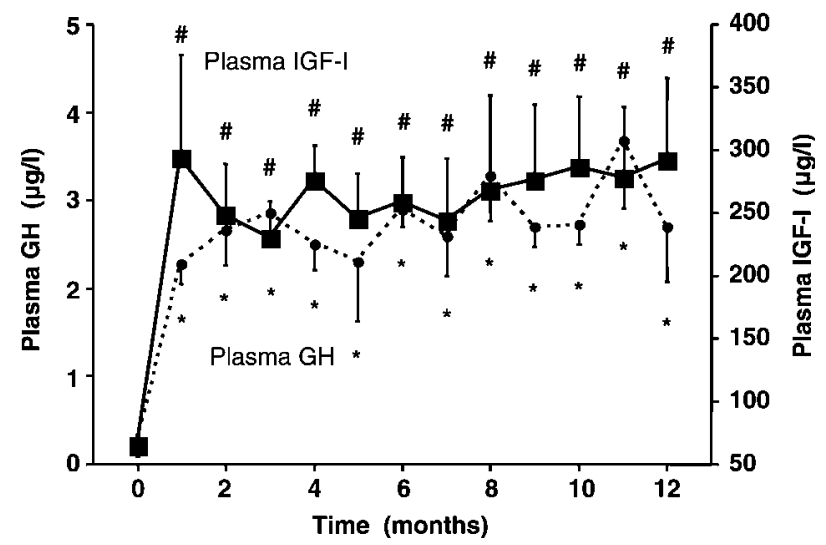

Figure 1 Effect of rhGH on plasma GH $(\bullet)$ and IGF-I levels ( $\square$ ). Mean \pm S.E. values are shown. ${ }^{*} P<0.05$ versus time $0(\mathrm{GH})$; ${ }^{\#} P<0.05$ versus time 0 (IGF-I).

significantly $(P=0.038)$. The neutrophil counts increased at 2, 3, 7, 8, 9, 11 and 12 months after the start of rhGH administration compared with $2822 \pm$ 377 neutrophils/ $\mu \mathrm{l}$ at time 0 . There were no changes in lymphocyte, monocyte or eosinophil counts. There were no abnormal findings of C-reactive protein or erythrocyte sedimentation rate during the study period.

\section{Discussion}

We demonstrated in this study that circulating G-CSF levels and neutrophil counts increased following rhGH administration in patients with adult $\mathrm{GH}$ deficiency. rhGH is commonly administrated by means of a bolus subcutaneous injection once a day. CSI of $\mathrm{GH}$ is more useful for some metabolic effects than a daily GH injection $(21,22)$. Laursen et al. (21) reported that CSI of GH for 4 weeks resulted in constant and increased serum GH levels, and higher levels of IGF-I and IGF-binding protein (IGFBP)-3 compared with a daily injection of $\mathrm{GH}$, and that it did not affect glucose

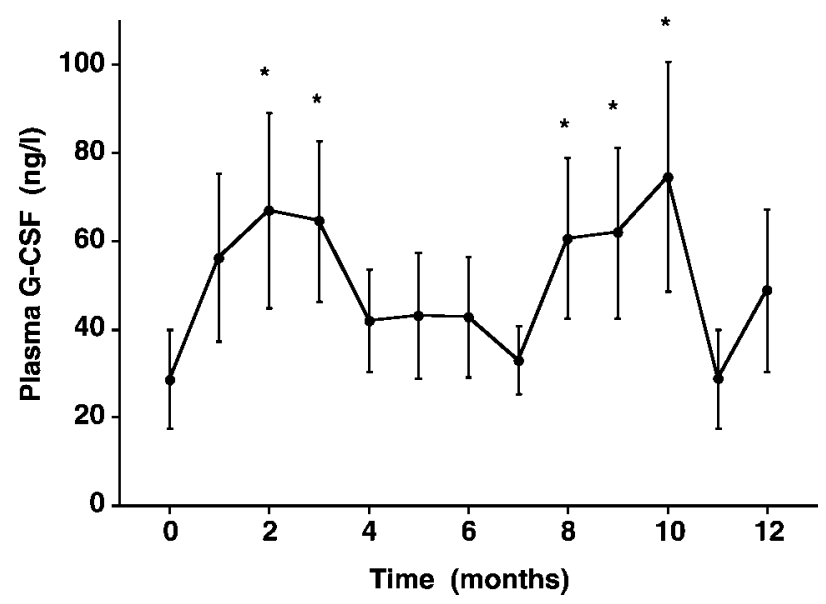

Figure 2 Effect of rhGH on plasma G-CSF levels. Mean \pm S.E. values are shown. ${ }^{\star} P<0.05$ versus time 0 .

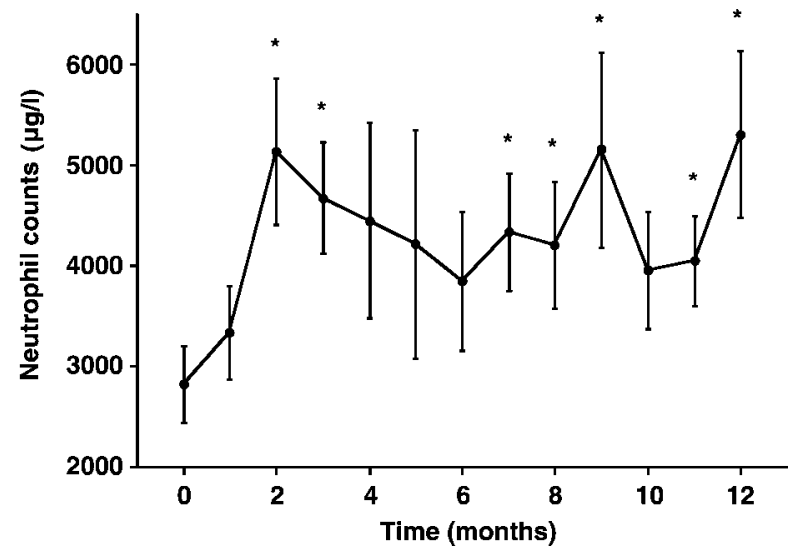

Figure 3 Effect of rhGH on neutrophil counts. Mean \pm S.E. values are shown. ${ }^{\star} P<0.05$ versus time 0 .

tolerance and produced lower insulin levels than with a daily GH injection. We reported previously that CSI of $\mathrm{GH}$ effectively increased erythropoietin secretion in anemic patients with chronic renal failure (23) and in malnourished predialysis anemic patients with diabetic nephropathy (24). As the present study was performed on a small number of patients, further investigation is required.

Based on the present study we would expect patients with acromegaly to have elevated or high normal neutrophil counts. However, as far as we know, few patients with acromegaly had elevated or high normal neutrophil counts. We think that acromegalic patients with very high plasma GH levels were associated with increased circulating plasma volume. Therefore, neutrophil counts might not reflect the true neutrophil counts for hemodilution.

IGF-I is also known to potentiate the stimulating effect on hematopoietic cells (25-27). It was reported that IGF-I promoted granulocyte functions by increasing granulocyte longevity (28) and that IGF-I administration enhanced lymphoid and myeloid reconstitution after allogenic bone marrow transplantation (29). However, there is no report about the relation between IGF-I and G-CSF. The present study suggests that GH and/or IGF-I may stimulate neutrophil production via G-CSF stimulation. As many cells secreting G-CSF possess both GH and IGF-I receptors, it was impossible to hypothesize whether these two hormones possess independent direct and indirect (via G-CSF production) granulopoietic effects in vivo.

We demonstrated that long-term treatment with rhGH raised plasma G-CSF levels within the initial 2 weeks in patients with adult GH deficiency. Subsequently, neutrophil counts increased to the normal range in association with suppressed plasma G-CSF levels in these patients treated with rhGH. The phenomenon that plasma G-CSF levels fall with an increase of neutrophil count after G-CSF elevation is often presented (30-33). Layton et al. (31) found a 
decrease in circulating G-CSF levels on neutrophil regeneration in patients with intravenous continuous G-CSF infusion after chemotherapy. A similar reaction between neutrophil counts and circulating G-CSF levels was found when recombinant G-CSF was administered by daily subcutaneous injections in patients (32) and healthy subjects (33). Endogenous G-CSF levels were regulated under the potential feedback mechanism of the neutrophil counts (34). It was suggested that the number of neutrophils regulates the biological activity of G-CSF by absorbing and metabolizing the G-CSF (35), and incubation experiments on recombinant G-CSF with neutrophils in vitro resulted in decreased G-CSF concentration (36). However, the precise mechanism was not fully elucidated.

The possibility that $\mathrm{GH}$ exerts a negative influence on leukocytic systems has been reported $(37,38)$. Previous clinical studies have demonstrated an increased incidence of leukemia occurring in pediatric subjects treated with $\mathrm{GH}(37,38)$. However, other recent studies have provided no evidence of an increased incidence of leukemia or extracranial nonleukemic malignancies among patients without prior risk factors $(39-41)$. In the present study, GH stimulated neutrophil production within the normal range via G-CSF secretion in vivo.

The neutrophil counts might be affected by redistribution, premature release and decreased clearance from the blood, and G-CSF is known to lead to premature release as well as to increased production. We could not clarify, based on the present study, whether redistribution of neutrophils contributed to the change in neutrophil count. Therefore further largescale study is necessary.

Two important limitations of our study merit further discussion. First, the present study was not designed by placebo control study because of difficulty of long-term CSI using physiological saline in patients with adult $\mathrm{GH}$ deficiency. Plasma G-CSF levels showed no sex difference, and no apparent correlation with age, hematocrit or white blood cell counts, but significant correlation was observed between the plasma G-CSF level and neutrophil count in normal subjects. Plasma G-CSF level was lower in the morning than in the afternoon or at night (42). However, there is no report of a seasonal change in plasma G-CSF levels or neutrophil counts. Therefore, further placebo control studies are required. Second, the present study was carried out with only a few patients. Therefore, it may be thought of as a pilot study.

In summary, we demonstrated that CSI of rhGH for 12 months raised plasma G-CSF levels at 2 months after the start of rhGH administration in patients with adult GH deficiency. Neutrophil counts were changed with plasma G-CSF levels. These findings suggest that GH and/or IGF-I might stimulate neutrophil production via G-CSF.

\section{Acknowledgements}

This work was supported in part by grants from the Ministry of Education, Science and Culture, Japan, and the Growth Science Foundation, Japan. We are indebted to Mrs Akiko Kawakami for her secretarial help and Mrs Akiko Kanayama for her technical assistance.

\section{References}

1 Jepson JH \& McGarry EE. Hemopoiesis in pituitary dwarfs treated with human growth hormone and testosterone. Blood 197239 238-248.

2 Nagy E \& Berczi I. Pituitary dependence of bone marrow function. British Journal of Haematology 198971 457-462.

3 Kotzmann H, Riedl M, Clodi M, Barnas U, Kaider A, Hocker P \& Luger A. The influence of growth hormone substitution therapy on erythroid and myeloid progenitor cells and on peripheral blood cells in adult patients with growth hormone deficiency. European Journal of Clinical Investigation 199626 1175-1181.

4 Derfalvi B, Nemet K, Szalai C, Kenesei E, Sallay P, Tulassay T \& Falus A. In vitro effect of human recombinant growth hormone on lymphocyte and granulocyte function of healthy and uremic children. Immunology Letters 199863 41-47.

5 Ten Have SMTH, van der Lely AJ \& Lamberts SWJ. Increase in haemoglobin concentrations in growth hormone deficient adults during human recombinant growth hormone replacement therapy. Clinical Endocrinology 199747 565-570.

6 Sohmiya M \& Kato Y. Effect of long-term administration of recombinant human growth hormone ( $\mathrm{rhGH}$ ) on plasma erythropoietin (EPO) and hemoglobin levels in anemic patients with adult GH deficiency. Clinical Endocrinology 200155 749-754.

7 Souza LM, Boone TC, Gabrilove J, Lai PH, Zsebo KM, Murdock DC, Chazin VR, Bruszewski J, Lu H, Chen KK et al. Recombinant human granulocyte colony-stimulating factor: effects on normal and leukemic myeloid cells. Science 1986232 61-65.

8 Cohen AM, Zsebo KM, Inoue H, Hines D, Boone TC, Chazin VR, Tsai L, Ritch T \& Souza LM. In vivo stimulation of granulopoiesis by recombinant human granulocyte colony-stimulating factor. PNAS 198784 2484-2488.

9 Nagata S \& Fukunaga R. Granulocyte colony-stimulating factor and its receptor. Progress in Growth Factor Research 19913 131-141.

10 Vellenga E, Rambaldi A, Ernst TJ, Ostapovicz D \& Griffin JD. Independent regulation of $\mathrm{M}-\mathrm{CSF}$ and G-CSF gene expression in human monocytes. Blood 198871 1529-1532.

11 Zsebo KM, Yuschenkoff VN, Schiffer S, Chang D, McCall E, Dinarello CA, Brown MA, Altrock B \& Bagby GC Jr. Vascular endothelial cells and granulopoiesis: interleukin-1 stimulates release of G-CSF and GM-CSF. Blood 198871 99-103.

12 Kaushansky K, Lin N \& Adamson JW. Interleukin 1 stimulates fibroblasts to synthesize granulocyte-macrophage and granulocyte colony-stimulating factors. Mechanism for the hematopoietic response to inflammation. Journal of Clinical Investigation $1988 \mathbf{8 1}$ $92-97$.

13 Fibbe WE, Van Damme J, Billiau A, Goselink HM, Voogt PJ, Van Eeden G, Ralph P, Altrock BW \& Falkenburg JH. Interleukin 1 induces human marrow stromal cells in long-term culture to produce granulocyte colony-stimulating factor and macrophage colony-stimulating factor. Blood $1988 \mathbf{7 1} 430-435$.

14 Sallerfors B. Endogenous production and peripheral blood levels of granulocyte-macrophage (GM-) and granulocyte (G-) colonystimulating factors. Leukemia and Lymphoma 199413 235-247.

15 Wakayama T, Sohmiya M, Furuya H, Murakami Y \& Kato Y. Increased serum human granulocyte colony-stimulating factor (G-CSF) levels following intravenous infusion of high-dose methylprednisolone. Endocrine Journal 199643 67-72. 
16 Lenhoff S, Sallerfors B \& Olofsson T. IL-10 as an autocrine regulator of CSF secretion by monocytes: disparate effects on GMCSF and G-CSF secretion. Experimental Hematology $1998 \mathbf{2 6}$ 299-304.

17 Kooijman R, Berus D, Malur A, Delhase M \& Hooghe-Peters EL. Human neutrophils express GH-N gene transcripts and the pituitary transcription factor Pit-1b. Endocrinology $1997 \mathbf{1 3 8}$ 4481-4484.

18 Hattori N, Saito T, Yagyu T, Jiang BH, Kitagawa K \& Inagaki C. $\mathrm{GH}, \mathrm{GH}$ receptor, GH secretagogue receptor, and ghrelin expression in human T cells, B cells, and neutrophils. Journal of Clinical Endocrinology and Metabolism 200186 4284-4291.

19 Sohmiya M \& Kato Y. Renal clearance, metabolic clearance rate, and half-life of human growth hormone in young and aged subjects. Journal of Clinical Endocrinology and Metabolism $1992 \mathbf{7 5}$ 1487-1490.

20 Yamamoto H, Sohmiya M, Oka N \& Kato Y. Effects of aging and sex on plasma insulin-like growth factor I (IGF-I) levels in normal adults. Acta Endocrinologica 1991124 497-500.

21 Laursen T, Jorgensen JO, Jakobsen G, Hansen B \& Christiansen JS. Continuous infusion versus daily injections of growth hormone (GH) for 4 weeks in GH-deficient patients. Journal of Clinical Endocrinology and Metabolism $1995 \mathbf{8 0} 2410-2418$.

22 Johansson JO, Oscarsson J, Bjarnason R \& Bengtsson BA. Two weeks of daily injections and continuous infusion of recombinant human growth hormone (GH) in GH-deficient adults: I. Effects on insulin-like growth factor-I (IGF-I), GH and IGF binding proteins, and glucose homeostasis. Metabolism $199645362-369$.

23 Sohmiya M, Ishikawa K \& Kato Y. Stimulation of erythropoietin secretion by continuous subcutaneous infusion of recombinant human $\mathrm{GH}$ in anemic patients with chronic renal failure. European Journal of Endocrinology 1998138 302-306.

24 Sohmiya M, Kakiba T \& Kato Y. Therapeutic use of continuous subcutaneous infusion of human erythropoietin in malnourished predialysis anemic patients with diabetic nephropathy. European Journal of Endocrinology 1998139 367-370.

25 Merchav S, Tatarsky I, Hochberg Z. Enhancement of human granulopoiesis in vitro by biosynthetic insulin-like growth factor $\mathrm{I} /$ somatomedin $\mathrm{C}$ and human growth hormone. Journal of Clinical Investigation $1988 \mathbf{8 1} 791-797$.

26 Bjerknes R \& Aarskog D. Priming of human polymorphonuclear neutrophilic leukocytes by insulin-like growth factor I: increased phagocytic capacity, complement receptor expression, degranulation, and oxidative burst. Journal of Clinical Endocrinology and Metabolism $1995 \mathbf{8 0} 1948-1955$.

27 Fu YK, Arkins S, Wang BS \& Kelley KW. A novel role of growth hormone and insulin-like growth factor-I. Priming neutrophils for superoxide anion secretion. Journal of Immunology $1991 \mathbf{1 4 6}$ 1602-1608.

28 Kooijman R, Coppens A \& Hooghe-Peters E. Igf-I inhibits spontaneous apoptosis in human granulocytes. Endocrinology 2002 $1431206-1212$.

29 Alpdogan O, Muriglan SJ, Kappel BJ, Doubrovina E, Schmaltz C, Schiro R, Eng JM, Greenberg AS, Willis LM, Rotolo JA et al. Insulin-like growth factor-I enhances lymphoid and myeloid reconstitution after allogeneic bone marrow transplantation. Transplantation 200375 1977-1983.

30 Furuya H, Wakayama T, Ohguni S, Yamauchi K, Tanaka J, Hatazoe $\mathrm{T} \&$ Kato $\mathrm{Y}$. Effect of continuous subcutaneous administration of a small dose of granulocyte colony stimulating factor (G-CSF) by the use of a portable infusion pump in patients with non-Hodgkin's lymphoma receiving chemotherapy. International Journal of Hematology 199561 123-129.

31 Layton JE, Hockman H, Sheridan WP \& Morstyn G. Evidence for a novel in vivo control mechanism of granulopoiesis: mature cellrelated control of a regulatory growth factor. Blood $1989 \mathbf{7 4}$ 1303-1307.

32 Faulkner LB, Tucci F, Tamburini A, Tintori V, Lippi AA, Bambi F, Malentacca F, Azzari C, Gelli AM, Genovese F \& Bernini G. G-CSF serum pharmacokinetics during peripheral blood progenitor cell mobilization: neutrophil count-adjusted dosage might potentially improve mobilization and be more cost-effective. Bone Marrow Transplantation 199821 1091-1095.

$33 \mathrm{Xu} \mathrm{S}$, Hoglund $\mathrm{M}$ \& Venge $\mathrm{P}$. The effect of granulocyte colony-stimulating factor (G-CSF) on the degranulation of secondary granule proteins from human neutrophils in vivo may be indirect. British Journal of Haematology 199693 558-568.

34 Cairo MS, Suen Y, Sender L, Gillan ER, Ho W, Plunkett JM \& Van de Ven C. Circulating granulocyte colony-stimulating factor (G-CSF) levels after allogeneic and autologous bone marrow transplantation: endogenous G-CSF production correlates with myeloid engraftment. Blood 199279 1869-1873.

35 Lenhoff S, Rosberg B \& Olofsson T. Granulocyte interactions with GM-CSF and G-CSF secretion by endothelial cells and monocytes. European Cytokine Network 199910 525-532.

36 Kojima S, Matsuyama T, Kodera Y, Nishihira H, Ueda K, Shimbo T \& Nakahata T. Measurement of endogenous plasma granulocyte colony-stimulating factor in patients with acquired aplastic anemia by a sensitive chemiluminescent immunoassay. Blood 199687 1303-1308.

37 Watanabe S, Tsunematsu Y, Fujimoto J \& Komiyama A. Leukemia in patients treated with growth hormone. Lancet $198811159-$ 1160 .

38 Fradkin JE, Mills JL, Schonberger LB, Wysowski DK, Thomson R, Durako SJ \& Robison LL. Risk of leukemia after treatment with pituitary growth hormone. Journal of the American Medical Association $19932702829-2832$.

39 Stahnke N \& Zeisel HJ. Growth hormone therapy and leukaemia. European Journal of Pediatrics 1989148 591-596.

40 Nishi Y, Tanaka T, Takano K, Fujieda K, Igarashi Y, Hanew K, Hirano T, Yokoya S, Tachibana K, Saito T \& Watanabe S. Recent status of the occurrence of leukemia in growth hormone-treated patients in Japan. Journal of Clinical Endocrinology and Metabolism 199984 1961-1965.

41 Maneatis T, Baptista J, Connelly K \& Blethen S. Growth hormone safety update from the National Cooperative Growth Study. Journal of Pediatric Endocrinology and Metabolism 200013 (suppl 2) 1035-1044.

42 Takeuchi M, Tanimoto Y, Tada A, Soda R \& Takahashi K. Circadian rhythm of plasma levels of endogenous granulocyte colony stimulating factor in healthy volunteers. International Journal of Hematology $199664293-295$.

Received 7 June 2004

Accepted 18 October 2004 